\title{
Comportamentos antecipatórios pré-alimentação em cavalos mantidos em baias
}

Vanessa da Silva Jochem, Marcus Vinicius Machado de Carvalho, Ana Beatriz Almeida Torres, Maria José Hötzel, Denise Pereira Leme

*Autor correspondente

e-mail: deleme@hotmail.com

\section{Resumo}

A sociedade cada vez mais vem se preocupando com o bem-estar, seja ele de humanos ou de outras espécies, e, consequentemente, há um crescente aumento das cobranças na criação animal, principalmente para os animais que vivem confinados. Uma das formas de se verificar o nível de bem-estar animal é avaliando as alterações nos comportamentos antecipatórios da espécie. Portanto, o presente estudo teve como objetivo avaliar a presença de comportamentos antecipatórios dos cavalos mantidos em sistemas de confinamento em um centro equestre no estado de Santa Catarina. Foram selecionados dez animais adultos de trabalho leve, confinados em baias individuais, submetidos à alimentação fracionada em cinco refeições diárias, contendo três tipos de alimento: volumoso, concentrado comercial e aveia, além do sal mineral e da água à vontade. Os cavalos foram divididos em dois grupos: três cavalos com estereotipias (grupo COM) e sete sem estereotipias (grupo SEM). Cada cavalo foi observado por dez dias, em três momentos do dia, em duplicata, por um período de 20 minutos cada. As observações foram realizadas duas vezes no baseline (momento sem interferência comportamental conhecida), duas vezes no pré-alimentação (pré-aveia e pré-concentrado comercial) e duas vezes após as mesmas alimentações. 0 observador se posicionou a uma distância da baia que permitiu uma total visualização do animal, sem interferir no comportamento espontâneo do mesmo. Foram observadas e cronometradas transições comportamentais, considerando as trocas de todos os tipos de comportamentos expressados pelos cavalos (normais, anômalos e estereotipados). Os dados coletados foram tabulados em planilhas Excel, realizando-se a comparação de médias e calculando-se os erros padrões. Independente do grupo, foram verificadas manifestações de 20 comportamentos normais (deitar, cavar, relinchar, espojar, etc) e 22 comportamentos anômalos e estereotipias (coprofagia, lamber ou morder estrutura da baia, "dança do urso", morder a língua exposta, etc) durante todas as observações. Durante o baseline, os animais COM apresentaram 15,7 \pm 8,3 transições de comportamento, enquanto os 
animais SEM tiveram 3,0 \pm 0,9. No momento pré-alimentação, os animais COM tiveram 32,9 \pm 8,1 transições de comportamento e os SEM, 5,5 $\pm 0,5$. No momento pós-alimentação, os animais COM apresentaram 7,5 \pm 7 transições e os SEM, 3,0 \pm 1,0. Observou-se que do baseline para a pré-alimentação, o grupo COM aumentou $17,35 \pm 1,75$ vezes o número de transições comportamentais, enquanto no grupo SEM o aumento foi de $2,46 \pm 0,67$. Do baseline para o pós-alimentação, o grupo COM apresentou um aumento do número de transições comportamentais de 8,13 $\pm 5,06$, enquanto o grupo SEM apresentou aumento de 2,49 $\pm 0,07$. Do momento pós-alimentação para pré-alimentação, observou-se que nos cavalos COM o aumento do número de transições comportamentais foi de 25,48 $\pm 6,5$, enquanto no grupo SEM foi de 2,49 $\pm 0,64$. Por estes resultados, pode-se verificar que os cavalos com estereotipias apresentaram maior número de transições comportamentais nos três momentos diários, e apresentaram mais trocas de comportamentos do que os cavalos sem estereotipias nos momentos que antecederam a alimentação. 0 número de transições no momento pós-alimentação foi o menor para os dois grupos, o que pode estar relacionado com uma possível sensação de satisfação, seja pela ingestão do alimento ou pelo objetivo alcançado. Neste estudo foi possível verificar que todos os cavalos anteciparam o momento da alimentação manifestando maior frequência de transições de comportamento e, de forma oposta, mostraram-se mais passivos após as refeições.

Palavras-chave: Equinos. Manejo alimentar. Alojamento. 